Provided for non-commercial research and educational use only. Not for reproduction or distribution or commercial use.

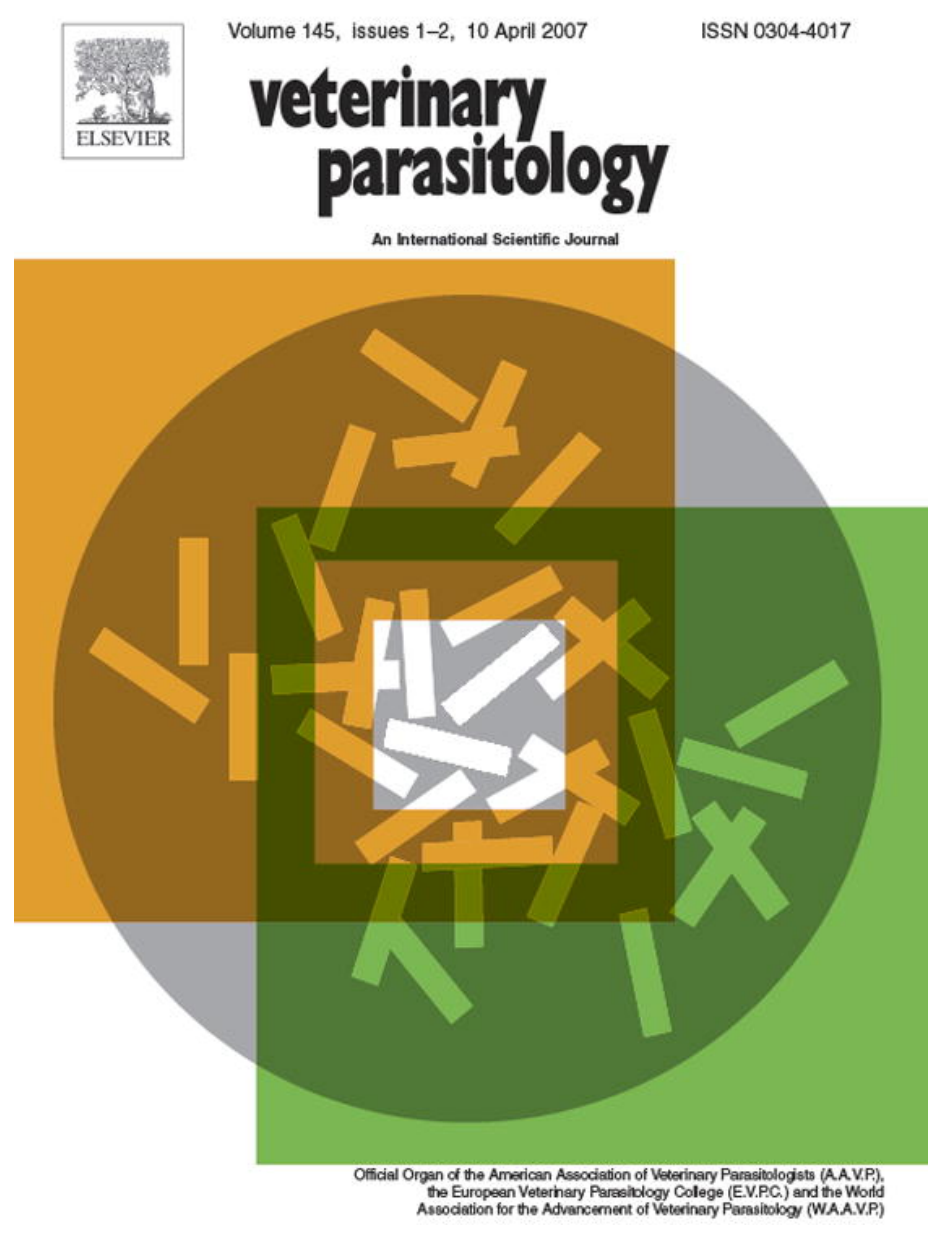

This article was originally published in a journal published by Elsevier, and the attached copy is provided by Elsevier for the author's benefit and for the benefit of the author's institution, for non-commercial research and educational use including without limitation use in instruction at your institution, sending it to specific colleagues that you know, and providing a copy to your institution's administrator.

All other uses, reproduction and distribution, including without limitation commercial reprints, selling or licensing copies or access,

or posting on open internet sites, your personal or institution's website or repository, are prohibited. For exceptions, permission may be sought for such use through Elsevier's permissions site at: 


\title{
Identification of Pentatrichomonas hominis in feline fecal samples by polymerase chain reaction assay
}

\author{
Jody L. Gookin ${ }^{\mathrm{a}, *}$, Stephen H. Stauffer ${ }^{\mathrm{a}}$, Michael G. Levy ${ }^{\mathrm{b}}$ \\ ${ }^{a}$ Department of Molecular Biomedical Sciences, College of Veterinary Medicine, North Carolina State University, \\ 4700 Hillsborough Street, Raleigh, NC 27606, United States \\ ${ }^{\mathrm{b}}$ Population Health and Pathobiology, College of Veterinary Medicine, North Carolina State University, \\ 4700 Hillsborough Street, Raleigh, NC 27606, United States
}

Received 22 August 2006; received in revised form 5 October 2006; accepted 27 October 2006

\begin{abstract}
Pentatrichomonas hominis is considered to be a commensal protozoan of the vertebrate digestive tract. On the basis of light microscopic examination of feces, some investigators presumptively identified $P$. hominis as a causative agent of feline diarrhea. However, molecular identification of $P$. hominis infection in the cat has not been reported. Another trichomonad, Tritrichomonas foetus, is recognized as an intestinal pathogen in cats and often presumptively diagnosed on the basis of the presence of trichomonads in diarrheic feces. It is of importance to determine if cats are natural hosts for P. hominis, as the presence of this organism could result in inaccurate assumption of $T$. foetus infection. In this study, we used a species-specific PCR assay to identify $P$. hominis $18 \mathrm{~S}$ rRNA genes in fecal samples collected from a convenience population of cats in which a high prevalence of $T$. foetus infection had been previously identified (cat show) or suspected (submitted for T. foetus diagnostic testing). The prevalence of $T$. foetus infection in these samples was $31 \%$ and $28.6 \%$, respectively. P. hominis infection was identified by PCR of DNA extracted from feces of five cats ( $1.9 \%$ and $2.1 \%$ of fecal samples, respectively). All cats in which $P$. hominis was identified were also infected with $T$. foetus. PCR identification of $P$. hominis infection in the cat should facilitate future studies to determine the pathogenicity of this species and enable differentiation of $P$. hominis from other known or as-yet unidentified species of trichomonads that may infect cats.
\end{abstract}

Published by Elsevier B.V.

Keywords: Tritrichomonas foetus; Trichomonas; Diarrhea; Pentatrichomonas hominis

\section{Introduction}

Trichomonads are obligate protozoan symbionts found in vertebrates and are considered to be among the most primitive of eukaryotic organisms. They are characterized morphologically by multiple anterior flagella and a single recurrent flagellum that functions

\footnotetext{
* Corresponding author. Tel.: +1 919513 6295; fax: +1 9195136465 .

E-mail address: Jody_Gookin@ncsu.edu (J.L. Gookin).
}

as an undulating membrane. Trophozoites reproduce by binary fission and undergo direct transmission from host to host without formation of environmentally stable cysts (Felleisen, 1999).

Genera of the Order Trichomonadida consist of both commensal and pathogenic species. When observed in the intestinal tract, trichomonads are often regarded as commensal due to the existence of Pentatrichomonas hominis, a non-pathogenic opportunist of the mammalian intestine (Wenrich, 1944). On the basis of light microscopic examination, some studies presumptively identified $P$. hominis as a causative agent of feline 
diarrhea, but molecular identification based on phylogenetic analysis of rRNA gene sequence data or experimental infections fulfilling Koch's postulates were not performed (Gookin et al., 1999; Romatowski, 1996, 2000). More recently, Tritrichomonas foetus has been identified as an intestinal pathogen in domestic cats, where infection within the colon results in mucosal inflammation and chronic diarrhea (Gookin et al., 2001; Levy et al., 2003; Yaeger and Gookin, 2005). In cats with clinical signs of diarrhea, a definitive diagnosis of T. foetus infection is based on PCR amplification of $T$. foetus rRNA genes from fecal DNA extracts (Gookin et al., 2002). In many instances however, $T$. foetus infection is presumptively diagnosed by microscopic observation of trichomonads in wet-mount preparations of feces or following fecal culture in specialized media (Gookin et al., 2003).

Importantly, the presence of $P$. hominis infection in cats has never been investigated using molecular techniques, nor has the possibility that $P$. hominis could be misidentified as $T$. foetus in cats with diarrhea. In the absence of fixation and staining, it is very difficult to distinguish live trophozoites of $T$. foetus from those of $P$. hominis and the specificity of many fecal culture techniques for selective cultivation of $T$. foetus is questionable. The aim of the present study was to determine if $P$. hominis infection could be detected, on the basis of PCR, in populations of cats suspected of having $T$. foetus infection.

\section{Materials and methods}

\subsection{Protozoa}

P. hominis (ATCC 30098) was obtained from the American Type Culture Collection (ATCC, Rockville, MD) and cultured at $37^{\circ} \mathrm{C}$ in recommended media. T. foetus (AF466751) was isolated from the feces of a 6-month-old sexually intact female domestic longhair cat that had chronic large-bowel diarrhea (Gookin et al., 2001). A logarithmic-phase culture of each was centrifuged for $5 \mathrm{~min}$ at $1500 \times g$. Genomic DNA was extracted from a $200 \mu \mathrm{l}$ aliquot of pelleted organisms using a QIAamp DNA Mini Kit (Qiagen, Valencia, CA) in accordance with manufacturer's instructions.

\subsection{Fecal samples}

\subsubsection{Pure-bred cats attending an international cat show (Group 1)}

Voided fecal samples were obtained from 117 cats attending an international cat show in Houston, Texas in
November 2001. Feces were frozen, shipped same-day on dry ice to the authors' laboratory and stored at $-20{ }^{\circ} \mathrm{C}$ for 8 months prior to DNA extraction and PCR for T. foetus (Gookin et al., 2004). DNA was additionally extracted from culture media inoculated with feces (InPouchTF ${ }^{\mathrm{TM}}$; Biomed Diagnostics, White City OR or Modified Diamond's media) in which trichomonads were identified (21/117 cats).

\subsubsection{Cats having feces submitted for $T$. foetus diagnostic testing by PCR (Group 2)}

Fecal samples obtained from 140 cats were preserved in isopropyl alcohol and submitted to the author's laboratory for $T$. foetus PCR testing from June 2005 to May 2006. Fecal samples were stored at $4{ }^{\circ} \mathrm{C}$ for less than 2 weeks prior to DNA extraction.

\subsubsection{Cats having diarrhea and trichomonosis} attributed to $T$. foetus infection on the basis of light microscopy and culture (Group 3)

Fecal samples were obtained from 20 cats with diarrhea and intestinal trichomonosis as determined by direct smear examination and/or protozoal culture of feces in modified Diamonds media as previously reported (Gookin et al., 1999). Fecal samples were stored at $-20{ }^{\circ} \mathrm{C}$ for less than 2 weeks prior to DNA extraction.

\subsection{DNA extraction}

DNA was extracted from each fecal sample using a QIAamp DNA Stool Mini Kit (Qiagen, Valencia, CA) that was modified for optimal elimination of PCR inhibitors as previously described (Gookin et al., 2002). Prior to PCR testing for P. hominis in the present study, DNA extracted from the feces of cats in Groups 1 and 3 were stored at $-80{ }^{\circ} \mathrm{C}$ for 5 years. DNA extracted from feces of cats in Group 2 was stored at $-80{ }^{\circ} \mathrm{C}$ for $\leq 12$ months.

\subsection{Single-tube nested PCR for T. foetus}

Each DNA sample was tested by PCR for $T$. foetus rRNA genes as previously described (Gookin et al., 2002). Results of PCR for detection of $T$. foetus in feces obtained from the cat show cats (Group 1) has been reported in a prior study (Gookin et al., 2004).

\subsection{PCR for bacterial $16 S$ rRNA gene}

Prior to PCR assay for $P$. hominis in the present study, all DNA samples were first subjected to PCR 
amplification of an $\approx 876 \mathrm{bp}$ fragment of bacterial $16 \mathrm{~S}$ rRNA gene sequences. By confirming PCR amplification of genes encoding bacterial 16S rRNA (which are anticipated to be abundant in all fecal DNA extracts) the possibility that a negative PCR result for $P$. hominis could be attributed to prolonged storage of DNA or the presence of endogenous PCR inhibitors in the extracted DNA was ruled out for each sample. Reaction conditions for 16S rRNA gene amplification were as follows: a $100 \mu \mathrm{l}$ reaction volume of PCR buffer II containing $2.5 \mathrm{U}$ AmpliTaq Gold DNA polymerase, 100 pmol each of primers 515F (5'-GTGCCAGCAGCCGCGGTAA- $3^{\prime}$ ) and 1391R (5'-GACGGGCGGTGAGTGCA-3'), $200 \mu \mathrm{M}$ each deoxynucleotide triphosphate, $10 \mu \mathrm{g}$ of bovine serum albumin, and $5 \mu \mathrm{l}$ of DNA template. DNA amplification was performed at the following temperature profile: initial denaturation at $95{ }^{\circ} \mathrm{C}$ for $5 \mathrm{~min}$; denaturation at $95{ }^{\circ} \mathrm{C}$ for $1 \mathrm{~min}$, annealing at $48{ }^{\circ} \mathrm{C}$ for $1 \mathrm{~min}$, and extension at $72{ }^{\circ} \mathrm{C}$ for $2 \mathrm{~min}$ for 50 cycles, followed by a final extension for $5 \mathrm{~min}$ at $72{ }^{\circ} \mathrm{C}$.

\subsection{P. hominis-specific primers}

P. hominis species-specific primers (Th3 and Th5) designed to amplify a $339 \mathrm{bp}$ sequence of the $18 \mathrm{~S}$ rRNA gene were synthesized on the basis of their published sequences (Integrated DNA Technologies; Coralville, IA) (Crucitti et al., 2004). The specificity of the primer pair for P. hominis was established previously by PCR using genomic DNA isolated from pure cultures of 17 different microorganisms including trichomonads (including $T$. foetus) and normal or pathogenic flora of the urogenital and gastrointestinal tracts (Crucitti et al., 2004).

\subsection{Amplification of P. hominis DNA}

PCR was carried out in a $100 \mu$ l reaction volume of $1 \times$ PCR Buffer II with $2.5 \mathrm{U}$ AmpliTaq Gold DNA polymerase (Applied Biosystems; Foster City, CA), 100 pmol each of primers Th3 (5'-TGTAAACGATGCCGACAGAG-3') and Th5 (5'-CAACACTGAAGCCAATGCGAGG-3'), $200 \mu \mathrm{M}$ of each deoxynucleoside triphosphate (dNTP), $10 \mu \mathrm{g}$ of bovine serum albumin (BSA; New England Biolabs, Beverly, MA), $2.5 \mathrm{mM} \mathrm{MgCl}_{2}$, and $5 \mu \mathrm{l}$ of DNA template per reaction.

DNA amplification was performed in an iCycler with the following profile: initial denaturation at $95{ }^{\circ} \mathrm{C}$ for $5 \mathrm{~min}$, denaturation at $95^{\circ} \mathrm{C}$ for $1 \mathrm{~min}$, annealing at $68{ }^{\circ} \mathrm{C}$ for $1 \mathrm{~min}$, and extension at $72{ }^{\circ} \mathrm{C}$ for $2 \mathrm{~min}$ for 50 cycles, and a final extension at $72{ }^{\circ} \mathrm{C}$ for $5 \mathrm{~min}$.
Amplicons were visualized by UV illumination after electrophoresis of $10 \mu \mathrm{l}$ of the reaction solution in a $1.5 \%$ agarose gel containing ethidium bromide. Reaction products were purified (QIAquick PCR Purification Kit; Qiagen, Valencia, CA) and sequenced by a commercial laboratory (Davis Sequencing, University of California, Davis).

\subsection{Detection of inhibitors and controls}

To avoid PCR contamination, DNA extractions, reaction preparation, thermal cycling, electrophoresis and detection of amplicons were performed in separate areas of the laboratory. During DNA extractions, duplicate tubes containing feces with no $P$. hominis and tubes containing PBS were processed in parallel with other study samples to detect any genomic DNA contamination. Negative control tubes were included in each PCR experiment to detect any amplicon contamination. Instead of sample DNA, these tubes received either $5 \mu \mathrm{l}$ of sterile water, $5 \mu \mathrm{l}$ of DNA extracted from feces containing no $P$. hominis, or $5 \mu \mathrm{l}$ of "DNA" extracted from sterile PBS. A single positive control tube was included in each PCR experiment and this tube received $0.5 \mu \mathrm{l}(20 \mathrm{ng})$ of purified $P$. hominis genomic DNA (ATCC 30098) and $4.5 \mu l$ sterile water instead of sample DNA.

\section{Results}

\subsection{Exclusion of samples on the basis of PCR amplification of $16 S$ rRNA genes}

$\mathrm{An} \approx 876$ bp gene product of bacterial 16S rRNA was amplified from DNA extracted from the feces of 103/ $117(88 \%)$ cats attending the international cat show (Group 1), 20/21 trophozoite-positive fecal cultures derived from the same cat show cats, 140/140 (100\%) cats having feces submitted to the author's laboratory for PCR testing for T. foetus (Group 2), and 20/20 $(100 \%)$ cats having diarrhea in which trichomonads were identified by light microscopy either before or after culture (Group 3). All DNA samples failing to amplify bacterial $16 \mathrm{~S}$ rRNA genes were excluded from subsequent PCR analysis.

\subsection{PCR amplification of partial $18 S$ rRNA gene of $P$. hominis}

A $339 \mathrm{bp}$ product of the $18 \mathrm{~S}$ rRNA gene of $P$. hominis was amplified from DNA extracted from the feces of $2 / 103(1.9 \%)$ cats attending the interna- 


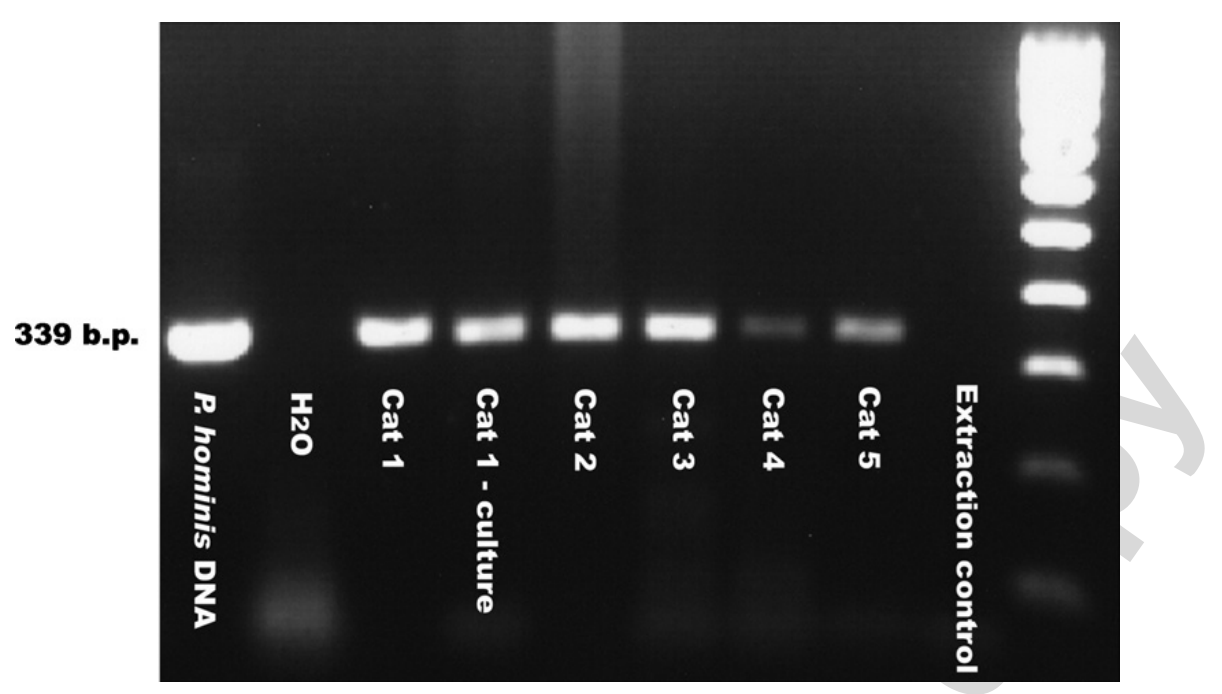

Fig. 1. PCR amplification products obtained from the feces of five cats using species-specific primers recognizing the 18S rRNA gene of $P$. hominis.

tional cat show (Group 1) (Fig. 1, cats 1-2). For one of these cats, $P$. hominis was also identified by PCR after culture of feces in modified Diamonds but not InPouchTF ${ }^{\mathrm{TM}}$ medium. The remaining 19 cultures in which trichomonads were identified were PCR-negative for $P$. hominis. The morphology of these trichomonads was not examined.

A $339 \mathrm{bp}$ product of the $18 \mathrm{~S}$ rRNA gene of $P$. hominis was amplified from the feces of 3/140 (2.1\%) cats in which suspected $T$. foetus infection prompted submission of feces for PCR testing (Group 2) (Fig. 1, cats 3-5). In comparison, 40/140 (28.6\%) of the same fecal samples tested positive by PCR for the presence of $T$. foetus rRNA genes. Feces from all three cats in which $P$. hominis genes were amplified were also PCR-positive for $T$. foetus. Two cats were from a multiple-cat household in Alaska; a 2.5-year-old spayed female Abyssinian and a 2.5-year-old neutered male Abyssinian. The remaining cat was a 6-month-old female Sphinx from a multiple-cat household in Ohio. Trophozoites were observed by light microscopy of feces from $2 / 3$ of the cats. Numbers of flagella present on the organisms was not reported.

Amplification of $P$. hominis rRNA genes was not observed after PCR of DNA extracted from the feces of 20 cats having diarrhea in which trichomonads were identified by light microscopy or after culture in a prior report (Group 3). Amplification of the gene encoding $P$. hominis 18S rRNA was not observed in any negativecontrol DNA extraction or PCR reaction samples.

Bi-directional analysis of each $339 \mathrm{bp}$ amplification product (Fig. 1) was identical and excluding the primer regions they shared $>99 \%$ sequence identity to $P$. hominis sequences in Genbank (AY758392 and AF124609). The feline sequences (Genbank
DQ899948) differ from each sequence in Genbank by only $1 \mathrm{bp}$ substitution.

\section{Discussion}

In the present study, we sought to determine if $P$. hominis infection could be identified in the cat; an occurrence that could complicate presumptive diagnosis of $T$. foetus in cats with trichomonosis and diarrhea. Accordingly, we used species-specific primers (Crucitti et al., 2004) under our own assay conditions to identify $P$. hominis 18S rRNA genes in a convenience population of fecal samples from cats in which a high prevalence of $T$. foetus infection had been previously identified (Group 1) or suspected (Group 2). The prevalence of T. foetus infection in these samples was $31 \%$ and $28.6 \%$, respectively. In comparison, the prevalence of $P$. hominis infection, as identified by PCR in the same samples, was $1.9 \%$ and $2.1 \%$. P. hominis was not identified in any fecal samples that were not also positive for $T$. foetus infection. Whether the prevalence of $P$. hominis infection would be similar in cats without risk factors for T. foetus infection will need to be determined by subsequent studies. The pathogenic potential of $P$. hominis in the cat remains unknown, however isolated infection with $P$. hominis did not appear to prompt submission of feces for $T$. foetus diagnostic testing from the cats reported here.

In the present study, $P$. hominis infection did not appear to contribute to misdiagnosis of $T$. foetus infection because co-infection was identified in all $P$. hominis-infected cats. It is possible however, that fecal samples in which trichomonads were identified were not sent for PCR testing due to presumption of $T$. foetus infection, when in fact the trichomonads were $P$. hominis. $P$. hominis DNA was not detected in any 
InPouchTF ${ }^{\mathrm{TM}}$ cultures of feces from cats in which $P$. hominis infection was identified. Prior studies have also failed to demonstrate survival of $P$. hominis in InPouchTF ${ }^{\mathrm{TM}}$ media for durations greater than $24 \mathrm{~h}$ (personal communication, Brian O'Quin, Biomed Diagnostics) (Gookin et al., 2003). Other means of fecal protozoal culture (such as modified Diamond's medium) may foster growth of many different species of trichomonads and, therefore, T. foetus infection should not be presumed. In conclusion, PCR identification of $P$. hominis infection in the cat should facilitate future studies to determine the pathogenicity of this species and enable the differentiation of $P$. hominis from other known or novel species of trichomonads that may infect cats.

\section{Acknowledgment}

The authors thank Matthew Poore for technical assistance.

\section{References}

Crucitti, T., Abdellati, S., Ross, D.A., Changalucha, J., Dyck, E., Buve, A., 2004. Detection of Pentatrichomonas hominis DNA in biological specimens by PCR. Lett. Appl. Microbiol. 38, 510-516.

Felleisen, R.S., 1999. Host-parasite interaction in bovine infection with Tritrichomonas foetus. Microbes Infect. 1, 807-816.
Gookin, J.L., Birkenheuer, A.J., Breitschwerdt, E.B., Levy, M.G., 2002. Single-tube nested PCR for detection of Tritrichomonas foetus in feline feces. J. Clin. Microbiol. 40, 4126-4130.

Gookin, J.L., Breitschwerdt, E.B., Levy, M.G., Gager, R.B., Benrud, J.G., 1999. Diarrhea associated with trichomonosis in cats. J. Am. Vet. Med. Assoc. 215, 1450-1454.

Gookin, J.L., Foster, D.M., Poore, M.F., Stebbins, M.E., Levy, M.G., 2003. Use of a commercially available culture system for diagnosis of Tritrichomonas foetus infection in cats. J. Am. Vet. Med. Assoc. 222, 1376-1379.

Gookin, J.L., Levy, M.G., Law, J.M., Papich, M.G., Poore, M.F., Breitschwerdt, E.B., 2001. Experimental infection of cats with Tritrichomonas foetus. Am. J. Vet. Res. 62, 1690-1697.

Gookin, J.L., Stebbins, M.E., Hunt, E., Burlone, K., Fulton, M., Hochel, R., Talaat, M., Poore, M., Levy, M.G., 2004. Prevalence of and risk factors for feline Tritrichomonas foetus and giardia infection. J. Clin. Microbiol. 42, 2707-2710.

Levy, M.G., Gookin, J.L., Poore, M., Birkenheuer, A.J., Dykstra, M.J., Litaker, R.W., 2003. Tritrichomonas foetus and not Pentatrichomonas hominis is the etiologic agent of feline trichomonal diarrhea. J. Parasitol. 89, 99-104.

Romatowski, J., 1996. An uncommon protozoan parasite (Pentatrichomonas hominis) associated with colitis in three cats. Feline Pract. 24, 10-14.

Romatowski, J., 2000. Pentatrichomonas hominis infection in four kittens. J. Am. Vet. Med. Assoc. 216, 1270-1272.

Wenrich, D.H., 1944. Morphology of the intestinal trichomonad flagellates in man and of similar forms in monkeys, cats, dogs, and rats. J. Morphol. 74, 189-211.

Yaeger, M.J., Gookin, J.L., 2005. Histologic features associated with Tritrichomonas foetus-induced colitis in domestic cats. Vet. Pathol. 42, 797-804. 